\title{
The role of fungal taxa and developmental stage of mushrooms in determining the composition of the mycophagous insect community in a Japanese forest
}

\author{
SATOSHI YAMASHITA* and NAOKI HIJII
}

Laboratory of Forest Protection, Graduate School of Bioagricultural Sciences, Nagoya University, Nagoya 464-8601, Japan

Key words. Chemical components, community structure, microbes, mushrooms, mycophagous insects

\begin{abstract}
We hypothesize that differences in fungal taxonomic groups may exert a direct influence on the composition of mycophagous insect communities, and that the relative importance of taxonomy compared to other fungal traits may change as the mushrooms decay. We conducted a 3-year field survey and analyzed the species composition of mycophagous insect communities using partial canonical correspondence analysis (partial CCA). We collected 2457 mushrooms belonging to 27 genera, and 4616 insects belonging to 16 families emerged from 439 of the mushrooms. For the whole insect community, fungal genera explained 10-19\% of the total variance in the family composition of the insect communities of mushrooms at different developmental stages. Only the fungal genus Collybia significantly affected the community composition almost irrespective of developmental stage. In the drosophilid community, which consisted of 844 individuals from 9 species, fungal genera explained 19-34\% of the total variance. Some fungal genera, such as Amanita and Collybia, affected the drosophilid community, but not at all developmental stages. The number of fungal genera that significantly affected the insect community composition did not differ among fungal stages both in the whole insect community and in the drosophilid community. Thus, our former hypothesis was supported by the present analysis, whereas the latter was not. However, the percentages of variance explained by fungal genera were rather small. This suggests that the importance of fungal genera is likely to be less significant than that of other selection pressures in determining the species composition of mycophagous insect communities.
\end{abstract}

\section{INTRODUCTION}

Mycophagous insects are generally recognized as polyphagous insects (Hackman \& Meinander, 1979; Hanski, 1989), and Hanski (1989) proposed two compatible hypotheses to explain why polyphagy is widely observed in mycophagous insect communities. The quantity hypothesis proposes that polyphagy is due to the low predictability of occurrence of fungal fruiting bodies (Jaenike, 1978), and the quality hypothesis proposes that differences in chemical traits between host species are not a major barrier to wider host use.

Species composition of mycophagous insect communities differ depending on the traits of the fruiting bodies they use; the tough and long-lived fruiting bodies of Aphyllophorales (bracket fungi) versus the fragile and ephemeral ones of Agaricales (mushrooms). Many studies have revealed that insects feeding on bracket fungi are generally mono- or oligophagous beetles (Ashe, 1984; Lawrence, 1989; Komonen, 2001), whereas those feeding on mushrooms are generally polyphagous flies (Hackman \& Meinander, 1979; Hanski, 1989). Fruiting bodies of Aphyllophorales are likely to be more predictable than those of Agaricales, and this trait may facilitate monophagy on bracket fungi and polyphagy on mushrooms (Courtney et al., 1990; Jonsell \& Nordlander, 2004).

Jonsell \& Nordlander (2004) surveyed the mycophagous beetles feeding on bracket fungi and proposed that polyphagous insects use decaying fruiting bodies to avoid the fungal chemical defenses (Kukor \& Martin, 1987). Agaric fruiting bodies (mushrooms) contain insecticidal compounds that affect non-mycophagous insects (Jaenike et al., 1983) and the toxicity differs among fungal species (Mier et al., 1996). It is proposed that these fungal insecticides do not affect mycophagous insects that are adapted to them (Jaenike et al., 1983; Hanski, 1989), but these studies did not take into account the state of decay of the mushrooms.

The odour of Coriolus versicolor (Aphyllophorales) change with the age of its fruiting bodies and two species of mycophagous beetles time their attack according to the odour of the fungi (Guevara et al., 2000). The odour of Fomitopsis pinicola (Aphyllophorales) and Fomes fomentarius (Aphyllophorales) also changes with the age of their fruiting bodies and their odour attracts some mycophagous beetles (Fäldt et al., 1999). Although the responses of mycophagous insects to the odour of agaric mushrooms have scarcely been studied, we observed that the amount of sap produced by Lactarius mushrooms, which contain an antifeedant to non-mycophagous beetles (Daniewski et al., 1993), declined as after the mushrooms decayed. This suggests that chemical components other than the odour of agaric fungi may also change with age.

Although differences in chemical compounds might play an important role in determining insect community structure, it is difficult to follow the qualitative and quantitative changes in the chemical compounds in mush-

\footnotetext{
* Present and corresponding address: Research Institute for Humanity and Nature, Kamigamo-motoyama 457-4, Kita-ku, Kyoto, 603-8047, Japan; e-mail: satosi-y@chikyu.ac.jp
} 
rooms in relation to the community structure of mycophagous insects. Thus, in this study the effect of fungal taxonomic group, which may indicate a difference in chemical compounds, on the composition of mycophagous insect communities was evaluated. We hypothesized that a difference in fungal taxonomic groups may exert a direct influence on the composition of mycophagous insect communities, and that the relative importance of fungal taxonomic group compared to other fungal traits may change as the mushrooms decay. We conducted a 3-year field survey and analyzed the emergence patterns of insects from mushrooms of different genera and developmental stages.

\section{MATERIAL AND METHODS}

\section{Study site}

Samples were collected in a mixed stand dominated by Japanese red pine (Pinus densiflora Sieb. et Zucc.), with a few Chamaecyparis obtusa (Sieb. et Zucc.) Endl. and Lindera triloba (Sieb. et Zucc.) Blume. The study site is situated within the Experimental Forest of Nagoya University, at Inabu in central Japan $\left(35^{\circ} 11^{\prime} \mathrm{N}, 137^{\circ} 33^{\prime} \mathrm{E}\right.$; ca. $1000 \mathrm{~m}$ a.s.l.). Three $10 \times 10 \mathrm{~m}$ plots were established at the study site, separated by $2-40 \mathrm{~m}$. Two of the three plots were close to one another, but supported different types of vegetation: one was dominated only by Japanese red pine, and the other by a mixture of Larix kaempferi, Betula ermanii and other broad-leaved trees (Yamashita \& Hijii, 2006). Each plot was divided into 100 quadrats, each $1 \mathrm{~m}$ square.

\section{Collection of mushrooms and emerging insects}

Mushrooms were collected from 1 July 1999 to 24 July 2002 at about 2-week (between 12 and 17 days) intervals, except during the winter season (January to April). Heavy rain prevented one survey on 14 September 2000. The genera and developmental stages of all the fruiting bodies of Agaricales (mushrooms) that were present in the plots on each sampling occasion were recorded. Identification to species of small mushrooms, such as those of the genera Marasmius and Mycena, which contain a large number of unknown species, as well as of decayed mushroom's is very difficult. Thus, only some of the mushrooms (that appeared mainly in 1999) were identified to the species level, all others were identified to genus (Yamashita \& Hijii, 2006), according to Imazeki \& Hongo (1987, 1989). Four developmental stages were distinguished: immature, soon after appearance (stage 1); fresh, with pileus slightly expanded (stage 2); intermediate, with pileus fully expanded (stage 3 ); and entirely decayed or dried out (stage 4). Up to five individuals belonging to the same genus at each developmental stage were collected from each quadrat. Large numbers of mushrooms appeared on 27 September 2000 and 28 September 2001, and as many mushrooms as possible were collected on these dates.

Each sample was placed on a piece of damp filter paper in a polyethylene container or paper bag in the field and brought to the laboratory. Each mushroom was weighed on a microbalance and then placed on a piece of filter paper on moistened sand in a polyethylene container with a lid (80-, 200-, 550-, and $4000 \mathrm{ml}$ volume, according to the size of the mushroom). The containers were kept in the laboratory under natural light conditions at $25^{\circ} \mathrm{C}$ and misted when necessary to prevent drying. For 3 months each container was inspected every 3 or 4 days to check for the emergence of adult insects. All insects were identified to family level and counted. For drosophilids, all the individuals were identified to species because they dominated the insect community and their taxonomy and ecological role is well known.

\section{Statistical analysis}

To reveal the effects of fungal genera on the community composition of mycophagous insects, we used canonical ordination (Jongman et al., 1995). Detrended correspondence analysis (DCA) was used to check the length of ordination axes (Jongman et al., 1995): if the length was smaller than 2 s.d., redundancy analysis was chosen, because the response curve could be monotonic: if the length was larger than 4 s.d., canonical correspondence analysis (CCA) was chosen, because the response curve could be unimodal: and if the length falls between 2 and 4, a unimodal model was chosen. After the DCA, we found that the lengths of the ordination axes for all the datasets except one were larger than 2, and thus CCA was chosen. These analyses were performed using Canoco 4.5 software (ter Braak \& Šmilauer, 2002), in which the relationships between a set of environmental variables (fungal genera) and an ordination score were plotted on ordination diagrams. In the diagrams, centroids for nominal variables depict the direction and magnitude of the relationships among explanatory variables and insect communities.

Because we aimed to reveal the effect of fungal quality, indicated by fungal genera, and developmental stage, on the species composition of mycophagous insect communities, it was important to exclude as many other factors as possible and therefore a partial CCA (a CCA with covariates: ter Braak \& Šmilauer, 2002) was performed. The size of mushrooms varies among fungal genera (Yamashita \& Hijii, 2003) and therefore could affect the composition of the mycophagous insect community (Worthen et al., 1996, 1998; Yamashita \& Hijii, 2003). Thus, the fresh weight of mushrooms was included in the analysis as a covariate. Month and year of mushroom collection were treated as covariates.

The total inertia, which is the total variance in the species data, was divided into three components: environmental data, covariables, and unexplained factors, and used to describe the extent to which the variance in the mycophagous insect community can be affected by these components (ter Braak \& $\breve{S}$ milauer, 2002). If $A$ denotes the total inertia and $B$ denotes the sum of all eigenvalues, the covariables explain $[(A-B) / A]^{*} 100 \%$ of the inertia. If $C$ denotes the sum of all canonical eigenvalues, our environmental variables explain $(C / A)^{*} 100 \%$, and the remainder is the unexplained fraction.

Each mushroom's genus was used as the environmental variable, and the month and year of collection and weight of mushrooms were treated as covariates. The genus of mushroom, month, and year were treated as dummy variables. The data for mushroom fresh weight was $\log _{10}$-transformed before analysis.

An analysis based on the number of emergents has many advantages but the number of individuals reared does not always represent an independent sample, because female insects tend to lay eggs in clutches. Therefore, both the datasets based on the number of emergents and on the presence or absence of insects were analyzed and the results were compared. The number of individual insects was log-transformed $\left(\log _{10}\right.$ (No. of individuals +1 )) before analysis. Families or species of insects that emerged from fewer than 5 mushrooms were not included in the analysis of the presence/absence data, which focused on the dominant insects. For both the analyses, mushroom genera with fewer than 10 samples were pooled and treated as a reference group. Parasitoids and predatory insects were excluded. The explanatory variables were tested by the automatic forward selection procedure in Canoco 4.5 (9999 randomizations). Biplots were focused on inter-species distances. 
TABLE 1. Number of mushrooms collected and their average fresh weight plus standard deviation for each fungal genus at each developmental stage.

\begin{tabular}{|c|c|c|c|c|c|}
\hline & & Stage 1 & Stage 2 & Stage 3 & Stage 4 \\
\hline Agaricaceae & Lepiota & $4(0.0 \pm 0.0)$ & $6(0.0 \pm 0.0)$ & $15(0.0 \pm 0.0)$ & $1(0.0)$ \\
\hline Amanitaceae & Amanita & $13(7.3 \pm 8.4)$ & $16(15.5 \pm 21.6)$ & $17(5.5 \pm 6.8)$ & $12(10.9 \pm 12.6)$ \\
\hline \multirow[t]{3}{*}{ Boletaceae } & Leccinum & - & $1(15.1)$ & $1(13.9)$ & $2(35.5 \pm 27.5)$ \\
\hline & Suillus & $3(5.9 \pm 6.7)$ & $7(19.3 \pm 16.8)$ & $3(10.1 \pm 10.7)$ & $2(1.4 \pm 1.1)$ \\
\hline & Tylopilus & $1(30.8)$ & $1(103.7)$ & - & - \\
\hline Coprinaceae & Psathyrella & $1(2.1)$ & $1(1.6)$ & - & - \\
\hline \multirow[t]{3}{*}{ Cortinariaceae } & Cortinarius & $4(1.0 \pm 0.2)$ & $19(2.0 \pm 1.9)$ & $3(2.7 \pm 2.1)$ & $4(0.9 \pm 0.6)$ \\
\hline & Dermocybe & - & $3(1.9 \pm 0.3)$ & $2(3.3 \pm 0.5)$ & - \\
\hline & Inocybe & $8(2.6 \pm 2.5)$ & $28(1.0 \pm 1.7)$ & $24(1.9 \pm 3.3)$ & $13(2.0 \pm 3.0)$ \\
\hline Gomphidiaceae & Gomphidius & - & $3(3.4 \pm 1.5)$ & - & $1(8.4)$ \\
\hline \multirow[t]{2}{*}{ Hygrophoraceae } & Camaerophyllus & - & - & $2(0.6 \pm 0.6)$ & - \\
\hline & Hygrocybe & $11(0.1 \pm 0.0)$ & $6(0.2 \pm 0.1)$ & $3(0.6 \pm 0.5)$ & $1(0.2)$ \\
\hline Paxillaceae & Paxillus & - & - & $3(3.4 \pm 2.2)$ & $2(3.9 \pm 0.4)$ \\
\hline Pluteaceae & Pluteus & - & - & $1(1.5)$ & - \\
\hline Rhodophyllaceae & Rhodophyllus & $27(1.1 \pm 1.0)$ & $113(2.8 \pm 2.6)$ & $48(3.4 \pm 3.3)$ & $30(3.0 \pm 3.0)$ \\
\hline \multirow[t]{2}{*}{ Russulaceae } & Lactarius & $43(1.1 \pm 0.8)$ & $99(3.1 \pm 2.2)$ & $56(4.7 \pm 3.4)$ & $25(3.0 \pm 2.4)$ \\
\hline & Russula & $3(7.6 \pm 4.7)$ & $9(9.6 \pm 5.4)$ & $5(4.7 \pm 4.4)$ & $10(3.4 \pm 2.1)$ \\
\hline \multirow[t]{2}{*}{ Strophariaceae } & Kuehneromyces & - & $3(0.4 \pm 0.1)$ & $3(0.3 \pm 0.2)$ & - \\
\hline & Naematoloma & - & - & - & $1(3.0)$ \\
\hline \multirow[t]{8}{*}{ Tricholomataceae } & Clitocybe & - & $3(0.8 \pm 0.4)$ & $2(0.5 \pm 0.1)$ & $1(0.4)$ \\
\hline & Collybia & $45(0.1 \pm 0.1)$ & $37(0.4 \pm 0.3)$ & $35(0.5 \pm 0.6)$ & $50(0.3 \pm 0.4)$ \\
\hline & Laccaria & $5(1.1 \pm 0.4)$ & $4(2.2 \pm 2.3)$ & $2(0.9 \pm 0.7)$ & $1(3.3)$ \\
\hline & Marasmiellus & $13(0.0 \pm 0.0)$ & $17(0.0 \pm 0.0)$ & $13(0.0 \pm 0.0)$ & $7(0.0 \pm 0.0)$ \\
\hline & Marasmius & $74(0.1 \pm 0.1)$ & $206(0.2 \pm 0.1)$ & $158(0.2 \pm 0.2)$ & $85(0.2 \pm 0.2)$ \\
\hline & Mycena & $132(0.0 \pm 0.0)$ & $420(0.1 \pm 0.2)$ & $213(0.1 \pm 0.2)$ & $130(0.1 \pm 0.1)$ \\
\hline & Oudemansiella & - & - & - & $1(1.8)$ \\
\hline & Tricholomopsisis & - & - & $2(0.3 \pm 0.0)$ & - \\
\hline Unidentified & & $8(0.3 \pm 0.8)$ & $27(0.5 \pm 1.2)$ & $25(0.5 \pm 0.6)$ & $18(0.2 \pm 0.2)$ \\
\hline
\end{tabular}

Stage 1 - immature, soon after appearance; stage 2 - fresh, with pileus expanded; stage 3 - intermediate, with pileus fully expanded; stage 4 - entirely decayed or dried out.

\section{RESULTS}

\section{Composition of mycophagous insect communities}

During the survey period, 2457 mushrooms belonging to 27 genera were collected (Table 1). The fresh weight of the mushrooms ranged from $0.0002 \mathrm{~g}$ to $104 \mathrm{~g}$. For each of the genera Amanita, Collybia, Lactarius, Marasmius, Mycena and Rhodophyllus, more than 10 individuals at each developmental stage were collected.

A total of 4616 insects belonging to 16 families emerged from 439 mushrooms (Table 2). Nitidulidae, Cecidomyiidae, Drosophilidae, Mycetophilidae, Phoridae and Psychodidae were dominant in terms of numbers of individuals (more than 100 individuals). They were frequently observed throughout the survey period, with members of each family emerging from more than 50 mushrooms. Only Hymenoptera were identified as parasitoids and no predatory insects were reared. A total of 844 drosophilid insects belonging to 9 species emerged from 85 mushrooms (Table 3). Drosophila bizonata Kikkawa \& Peng, D. orientacea Grimaldi, James \& Jaenike, D. unispina Okada, Hirtodrosophila alboralis Momma \&
Takada and $H$. sexvittata Okada each emerged from more than 10 mushrooms.

\section{Host use by mycophagous insects in relation to mushroom traits}

Whole insect community

Using the abundance (the number of individuals that emerged) data, a partial CCA for the whole survey period was performed. Total inertia at stage 1, 2, 3 and 4 was $5.66,7.84,6.45$ and 5.85, respectively. Fungal genera and covariables explained $28 \%-55 \%$ of the inertia. Fungal genera explained $14 \%$ at stage $1,15 \%$ at stage $2,13 \%$ at stage 3 and $10 \%$ at stage 4 . On the other hand, a partial CCA based on the presence/absence data showed that total inertia at stage 1, 2, 3 and 4 was 2.00, 4.70, 3.45 and 4.59, respectively. Fungal genera and covariables explained $32 \%-78 \%$ of the inertia. Fungal genera explained $12 \%$ at stage $1,17 \%$ at stage $2,19 \%$ at stage 3 and $10 \%$ at stage 4 .

Automatic forward selection revealed that, at stage 1, Marasmiellus and Collybia significantly affected the 
TABLE 2. Insects that emerged from agaric mushrooms at developmental stages 1, 2, 3 and 4.

\begin{tabular}{|c|c|c|c|c|c|c|c|c|c|c|c|c|c|c|c|c|c|c|c|c|c|}
\hline & Genera & Nit & Sca & Sta & UnC & $\mathrm{Cec}$ & Chi & Chl & Dro & $\mathrm{Hel}$ & Mus & Myc & Pho & Psy & Sci & Sph & Syr & Tip & UnD & Hym & Uni \\
\hline \multirow[t]{8}{*}{ Stage 1} & Amanita & - & - & - & - & 3 & - & - & - & - & - & 29 & 3 & 4 & 1 & - & - & 1 & - & 6 & 1 \\
\hline & Collybia & 28 & - & - & 1 & - & - & - & - & - & - & - & - & - & - & - & - & - & - & 2 & - \\
\hline & Inocybe & - & - & - & - & - & - & - & - & - & - & 1 & 16 & - & - & - & - & - & - & - & - \\
\hline & Laccaria & - & - & - & - & - & - & - & - & - & - & - & - & - & - & - & - & - & - & 1 & - \\
\hline & Lactarius & - & - & - & 3 & - & - & - & - & - & - & 17 & 42 & - & - & - & - & 7 & 1 & - & - \\
\hline & Marasmiellus & - & - & - & - & 5 & - & - & - & - & - & - & - & - & - & - & - & - & - & - & - \\
\hline & Mycena & - & - & - & - & - & - & - & - & - & - & - & 1 & - & - & - & - & - & - & 2 & - \\
\hline & Rhodophyllus & - & - & - & - & - & - & - & - & - & - & - & 8 & - & - & - & - & - & - & - & - \\
\hline \multirow[t]{17}{*}{ Stage 2} & Amanita & - & - & - & - & 14 & - & - & 65 & - & - & 7 & 102 & 49 & - & - & - & - & - & 1 & 6 \\
\hline & Clitocybe & - & - & - & - & - & - & - & - & - & - & - & 4 & - & - & - & - & - & - & - & - \\
\hline & Collybia & 54 & - & - & - & - & - & - & 12 & - & - & - & 27 & - & - & - & - & - & - & 12 & - \\
\hline & Cortinarius & - & - & - & - & 1 & - & 2 & - & - & - & 1 & - & 2 & - & - & - & - & - & - & - \\
\hline & Dermocybe & - & - & - & - & - & - & - & - & - & - & 2 & 9 & 1 & - & - & - & - & - & - & - \\
\hline & Gomphidius & - & - & - & - & - & - & - & - & - & - & 1 & - & - & - & - & - & - & - & - & - \\
\hline & Hygrocybe & - & - & - & - & - & - & - & - & - & - & - & 2 & - & - & - & - & - & - & - & - \\
\hline & Inocybe & - & - & - & - & - & - & - & - & - & - & 12 & 8 & - & - & - & - & - & - & - & - \\
\hline & Laccaria & - & - & - & - & - & - & - & - & - & - & 1 & - & - & - & - & - & - & - & - & - \\
\hline & Lactarius & - & - & 2 & - & 2 & - & - & 4 & 6 & - & 85 & 289 & - & 2 & - & - & 2 & - & 3 & 2 \\
\hline & Marasmiellus & - & - & - & - & 5 & - & - & - & - & - & - & - & - & - & - & - & - & - & - & - \\
\hline & Marasmius & - & - & - & - & 18 & - & - & - & - & - & - & - & - & - & - & - & - & - & - & - \\
\hline & Mycena & - & - & 6 & - & 41 & - & - & - & - & - & 14 & 121 & 1 & 1 & - & - & - & - & 14 & - \\
\hline & Rhodophyllus & - & 1 & - & - & - & - & - & - & - & - & 9 & 38 & 2 & - & - & - & - & - & 6 & - \\
\hline & Russula & - & - & - & - & - & - & - & - & - & - & 6 & - & - & - & - & - & - & - & 1 & - \\
\hline & Suillus & - & - & - & - & - & - & - & - & - & - & 9 & - & - & - & - & 1 & 39 & - & - & - \\
\hline & Unidentified & - & - & - & - & - & - & - & - & - & - & 1 & - & - & - & - & - & - & - & - & - \\
\hline \multirow[t]{17}{*}{ Stage 3} & Amanita & - & - & - & - & 25 & - & - & 135 & 1 & - & 12 & 124 & 190 & 1 & 2 & - & - & - & 1 & 3 \\
\hline & Collybia & 44 & - & - & 1 & - & - & - & 21 & - & - & - & 3 & - & - & - & - & - & - & 27 & - \\
\hline & Cortinarius & - & - & - & - & - & - & - & 1 & - & - & 3 & - & - & - & - & - & - & - & - & - \\
\hline & Dermocybe & - & - & - & - & - & - & - & - & - & - & - & 11 & - & - & - & - & - & - & - & - \\
\hline & Inocybe & - & - & - & - & 2 & - & - & 19 & - & - & 5 & 177 & 51 & - & - & - & - & - & 5 & - \\
\hline & Lactarius & - & - & - & - & 1 & - & - & 14 & 5 & - & 71 & 52 & 5 & - & - & - & 2 & 4 & 2 & 1 \\
\hline & Leccinum & - & - & - & - & - & - & - & 8 & - & - & - & 1 & 153 & - & - & - & - & - & - & - \\
\hline & Marasmiellus & - & - & - & - & 5 & - & - & - & - & - & - & - & - & - & - & - & - & - & - & - \\
\hline & Marasmius & - & - & 3 & - & 47 & - & - & - & - & - & 1 & - & - & - & - & - & - & - & 2 & - \\
\hline & Mycena & - & - & - & - & 6 & - & 5 & 20 & - & - & 3 & 44 & - & - & - & - & - & - & 1 & - \\
\hline & Paxillus & - & - & - & - & - & - & - & 3 & - & - & 1 & 1 & 6 & - & - & - & - & - & - & 1 \\
\hline & Pluteus & - & - & - & - & 1 & - & - & - & - & - & - & - & 13 & - & - & - & - & - & - & - \\
\hline & Rhodophyllus & - & - & - & - & - & - & - & 5 & - & - & 15 & 7 & 14 & 1 & - & - & - & - & - & - \\
\hline & Russula & - & - & - & - & 83 & - & - & 24 & - & - & 8 & 20 & - & - & - & - & - & - & - & 2 \\
\hline & Suillus & - & - & - & - & - & - & - & - & - & - & 8 & - & 5 & - & - & 1 & 17 & - & - & - \\
\hline & $\begin{array}{c}\text { Tricholo- } \\
\text { mopsis }\end{array}$ & - & - & - & - & - & - & - & - & - & - & - & - & - & - & - & - & - & - & 1 & - \\
\hline & Unidentified & - & - & - & - & - & - & - & - & - & - & - & 2 & - & - & - & - & - & - & - & - \\
\hline \multirow[t]{14}{*}{ Stage 4} & Amanita & 1 & - & - & - & 44 & - & - & 141 & - & 7 & 2 & 55 & 165 & - & - & - & 40 & 1 & 10 & 1 \\
\hline & Collybia & 18 & - & - & 5 & 1 & - & 23 & 111 & 4 & - & 1 & 4 & 37 & - & 13 & - & - & 2 & 3 & 1 \\
\hline & Cortinarius & - & - & - & - & - & - & - & 3 & - & - & - & - & - & - & - & - & - & - & - & - \\
\hline & Inocybe & - & - & - & - & - & - & 7 & 89 & 1 & - & - & 16 & 93 & - & - & - & - & - & - & 2 \\
\hline & Laccaria & - & - & - & - & - & - & - & - & - & - & 5 & - & - & - & - & - & 3 & - & - & - \\
\hline & Lactarius & - & - & - & 1 & 9 & - & - & 52 & - & - & 16 & 4 & 47 & - & 7 & - & 3 & - & - & 2 \\
\hline & Leccinum & - & - & - & - & - & - & - & 8 & 1 & - & 1 & 15 & 12 & - & - & - & 8 & - & - & - \\
\hline & Marasmiellus & - & - & - & - & 8 & - & - & - & - & - & - & - & - & - & - & - & - & - & - & - \\
\hline & Marasmius & - & - & - & - & 27 & - & 1 & 2 & 1 & - & - & 1 & 3 & - & 6 & - & - & - & - & - \\
\hline & Mycena & - & - & 1 & - & 9 & - & - & 5 & - & - & 1 & 35 & - & - & - & - & - & - & - & 4 \\
\hline & Paxillus & - & - & - & 1 & - & - & - & 9 & - & - & - & - & 99 & - & - & - & - & - & - & - \\
\hline & Rhodophyllus & - & - & - & - & - & - & - & 14 & - & - & 2 & 11 & 4 & - & - & - & - & - & 6 & - \\
\hline & Russula & - & - & - & - & - & 17 & - & 79 & - & - & 6 & 13 & 274 & - & 4 & - & 1 & - & 1 & 3 \\
\hline & Unidentified & - & - & - & - & 5 & - & - & - & - & - & - & - & - & - & - & - & - & - & - & - \\
\hline
\end{tabular}

Nit - Nitidulidae; Sca - Scaphidiidae; Sta - Staphilinidae, UnC - Unidentified Coleoptera; Cec - Cecidomyiidae; Chi - Chironomidae; Chl - Chloropidae; Dro - Drosophilidae; Hel - Heleomyzidae; Mus - Muscidae; Myc - Mycetophilidae; Pho - Phoridae; Psy - Psychodidae; Sci - Sciaridae; Sph - Sphaeroceridae; Syr - Syrphidae; Tip - Tipulidae; UnD - Unidentified Diptera; Hym - Hymenoptera; Uni - Unidentified; Stage 1 - immature, soon after appearance; Stage 2 - fresh, with pileus expanded; Stage 3 - intermediate, with pileus fully expanded; Stage 4 - entirely decayed or dried out. 
TABLE 3. Drosophilids that emerged from agaric mushrooms at developmental stages 2, 3 and 4.

\begin{tabular}{cccccccccccc}
\hline & Genera & Dang & Dbiz & Dori & Duni & Dsp1 & Dsp2 & Halb & Hmac & Hsex & Unid \\
\hline Stage 2 & Amanita & - & - & - & 19 & - & - & 34 & - & 11 & 1 \\
& Collybia & - & - & - & - & - & - & 3 & - & 9 & - \\
& Lactarius & - & - & - & 4 & - & - & - & - & - & - \\
\hline Stage 3 & Amanita & - & 43 & 9 & 48 & - & - & - & - & 34 & 1 \\
& Collybia & - & - & - & - & - & - & 11 & 3 & 6 & 1 \\
& Cortinarius & - & 1 & - & - & - & - & - & - & - & - \\
& Inocybe & - & 9 & - & - & - & - & 7 & - & 3 & - \\
& Lactarius & - & 1 & - & 3 & - & - & 6 & - & 2 & 2 \\
& Leccinum & - & - & - & - & - & - & - & - & 8 & - \\
& Mycena & - & - & - & 13 & - & - & 7 & - & - & - \\
& Paxillus & - & - & - & - & - & - & 3 & - & - & - \\
& Rhodophyllus & - & - & - & 5 & - & - & - & - & - & - \\
& Russula & - & - & - & - & - & - & - & - & 24 & - \\
\hline Stage 4 & Amanita & 5 & 7 & 11 & 52 & 10 & 2 & - & - & 54 & - \\
& Collybia & - & 1 & - & 11 & - & - & 86 & 9 & 3 & 1 \\
& Cortinarius & - & 3 & - & - & - & - & - & - & - & - \\
Inocybe & - & 27 & - & 61 & - & - & - & - & - & 1 \\
& Lactarius & - & 37 & 14 & 1 & - & - & - & - & - & - \\
Leccinum & - & 7 & - & - & - & - & - & - & - & 1 \\
Marasmius & - & - & - & 2 & - & - & - & - & - & - \\
Mycena & - & 2 & - & - & - & - & 3 & - & - & - \\
Paxillus & - & 9 & - & - & - & - & - & - & - & - \\
& Rhodophylus & - & 14 & - & - & - & - & - & - & - & - \\
Russula & 7 & 54 & 7 & - & - & - & 6 & - & 2 \\
\hline
\end{tabular}

Dang - Drosophila anguralis; Dbiz - D. bizonata; Dori - D. orientacea; Duni - D. unispina; Dsp1 - Drosophila sp. 1; Dsp2 - Drosophila sp. 2; Halb - Hirtodrosophila alboralis; Hmac - H. macromaculata; Hsex - H. sexvittata.; Unid - Unidentified individuals Stage 1 - immature, soon after appearance; Stage 2 - fresh, with pileus expanded; Stage 3 - intermediate, with pileus fully expanded; Stage 4 - entirely decayed or dried out. No drosophilids emerged from mushrooms at Stage 1.

composition of the insect community using either the abundance data or the presence/absence data. At stage 2 Amanita, Collybia, Cortinarius and Lactarius significantly affected the composition of the insect community based on the abundance data, and Amanita, Collybia, Lactarius and Marasmiellus based on the presence/absence data. At stage 3, Collybia, Lactarius and Marasmius, and at stage 4, only Collybia significantly affected the composition of the insect community using either datasets. At stage 3 based on presence/absence data, Marasmiellus also significantly affected community composition.

There were no significant differences in the number of genera of fungi that significantly affected the insect community composition at the different developmental stages ( $G$ - test for contingency table: $G=3.42, p=0.331$ for the abundance data, $G=4.407, p=0.221$ for the presence/absence data).

Partial CCA based on the abundance data revealed that only the fungal genus Marasmiellus, which is attacked by Cecidomyiidae, significantly affected the composition of the insect community at stage 1 (Fig. 1). At stage 2, Psychodidae and Drosophilidae were associated with $\mathrm{Ama}$ nita, Nitidulidae with Collybia, Chloropidae with Cortinarius and Heleomyzidae and Mycetophilidae with Lactarius. At stage 3, Nitidulidae were associated with Collybia, Heleomyzidae with Lactarius, and Staphilinidae with Marasmius. At stage 4, Nitidulidae, Chlorophidae and Heleomyzidae were associated with Collybia (Fig. 1).
Partial CCA based on the presence/absence data revealed that only the fungal genus Collybia, which is attacked by Nitidulidae, significantly affected the composition of the insect community at stage 1 (Figures are not shown). At stage 2, Cecidomyiidae and Psychodidae were associated with Amanita, Heleomyzidae with Lactarius and Cecidomyiidae with Marasmiellus. At stage 3, Nitidulidae were associated with Collybia, Mycetophilidae with Lactarius and Cecidomyiidae with Marasmiellus and Marasmius. At stage 4, only Collybia affected the composition of the insect community. Thus, relationships between Collybia and Nitidulidae at stage 2, between Lactarius and Heleomyzidae at stage 2, between Collybia and Nitidulidae at stage 3 and between Collybia and Nitidulidae, Chlorophidae, and Heleomyzidae at stage 4 were observed both in the datasets based on abundance and on presence or absence.

\section{Drosophilid community}

Based on the abundance data, fungal genera and covariables explained more than $50 \%$ of the inertia both at stage 3 and at stage 4. Fungal genera explained $34 \%$ of the variance at stage 3 and $19 \%$ at stage 4 . On the other hand, fungal genera and covariables explained about $65 \%$ of the inertia for the dataset based on presence or absence of insects. Fungal genera explained $27 \%$ of the variance at stage 3 and $25 \%$ at stage 4 .

At stage 3, forward selection in partial CCA based on the abundance data revealed that 5 fungal genera, Ama- 

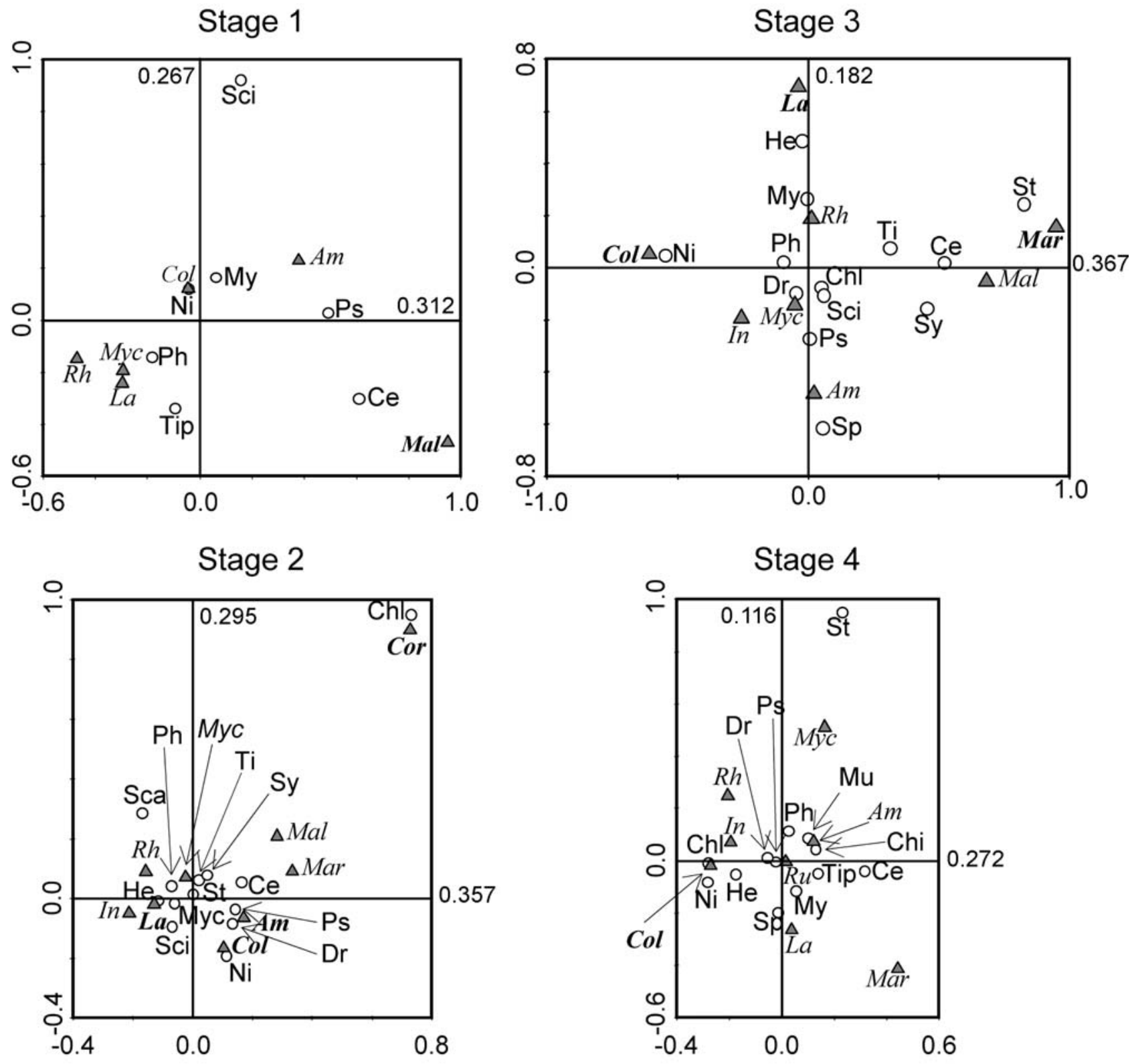

Fig. 1. Diagram of partial canonical correspondence analysis ordination for the corresponding positions of insect families (circles) based on abundance (the number of emerging insects) data. Environmental variables are indicated by black triangles. Figures along the axes are eigenvalues. Significant variables are shown in bold (Monte Carlo Permutation test, $p<0.05$ ). Abbreviations for fungi: Am - Amanita; Col - Collybia; Cor - Cortinarius; In - Inocybe; La - Lactarius; Mal - Marasmiellus; Mar - Marasmius; Myc Mycena; Rh-Rhodophyllus; Ru-Russula. Abbreviations for insects: Ce - Cecidomyiidae; Chi - Chironomidae; Chl, Chloropidae; Dr, Drosophilidae; He, Heleomyzidae; Mu - Muscidae; My - Mycetophilidae; Ni - Nitidulidae; Ph - Phoridae; Ps - Psychodidae; Sca - Scaphidiidae; Sci - Sciaridae; Sp - Sphaeroceridae; St - Staphilinidae; Sy - Syrphidae; Ti - Tipulidae.

nita, Collybia, Inocybe, Mycena and Rhodophyllus significantly affected the species composition of the drosophilid community at stage 3 (Fig. 2). Drosophila orientacea was associated with the genus Amanita, $H$. alboralis with Collybia, D. bizonata with Inocybe and $D$. unispina with Mycena and Rhodophyllus. At stage 4, however, only Collybia significantly affected the species composition of the drosophilid community (Fig. 2). Hirtodrosophila alboralis was associated with the genus Collybia.

Based on the presence/absence data, only Amanita significantly affected the species composition at stage 3 , and
Collybia, Lactarius, Marasmius and Mycena at stage 4. At stage $4, H$. alboralis was associated with the genera Collybia and Mycena, and D. orientacea with Lactarius (Figures not shown). Thus, the relationship between $H$. alboralis and Collybia at stage 4 was observed both in the datasets based on abundance and on presence/absence of drosophilids.

There were no significant differences in the number of the fungal genera that significantly affected the species composition of the drosophilid community at the different fungal developmental stages ( $G$ - test for contingency 


\section{Stage 3}
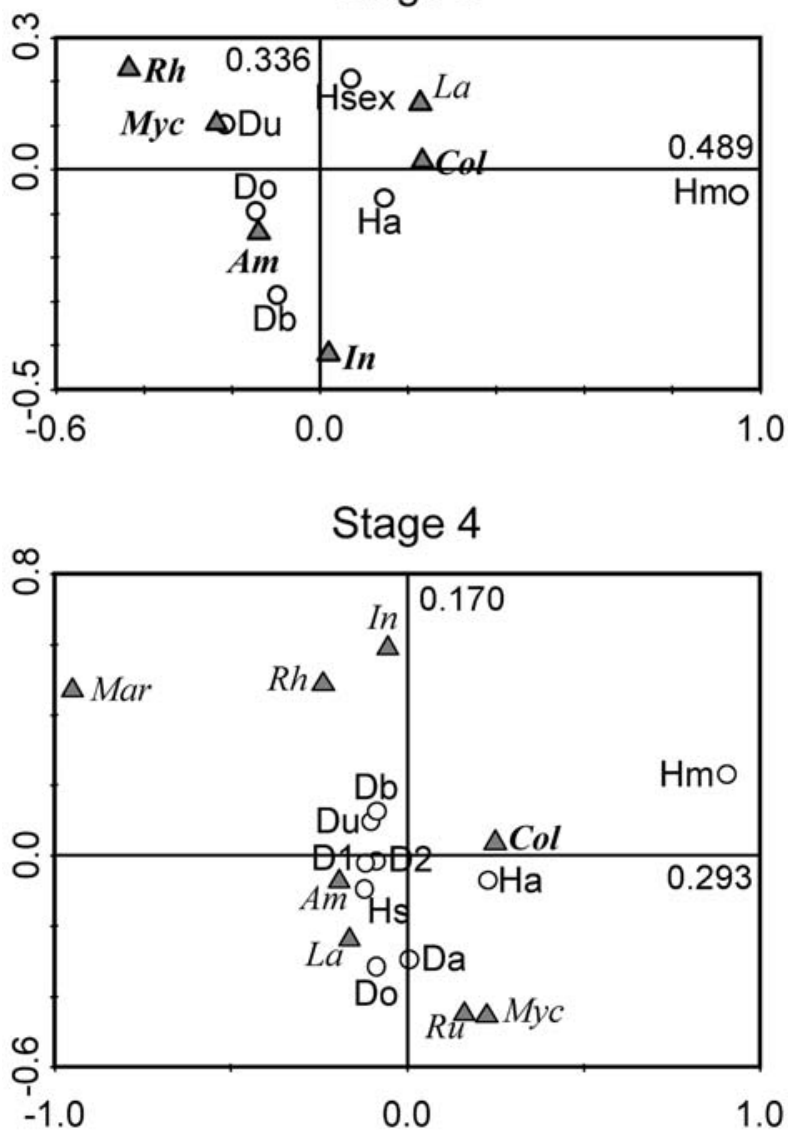

Fig. 2. Diagram of partial canonical correspondence analysis ordination for the corresponding positions of drosophilid species (circles) based on abundance of emerging drosophilids. Environmental variables are shown by black triangles. Figures along the axes are eigenvalues. Significant variables are shown in bold (Monte Carlo Permutation test, $p<0.05$ ). Abbreviations for fungi are given in Fig. 1. Abbreviations for drosophilid insects: $\mathrm{Da}-$ Drosophila anguralis; $\mathrm{Db}-D$. bizonata $; \mathrm{Do}-D$. orientacea; Du - D. unispina; D1 - Drosophila sp.1; D2 - Drosophila sp.2; Ha - Hirtodrosophila alboralis; $\mathrm{Hm}$ - H. macromaculata; $\mathrm{Hs}-H$. sexvittata.

table: $G=3.68, p=0.055$ for the abundance data, $G=$ $3.23, p=0.072$ for the presence/absence data).

\section{DISCUSSION}

Our hypothesis that a difference in the fungi may exert a direct influence on the composition of mycophagous insect communities was supported, but the other hypothesis that the relative importance of fungal genera compared to other fungal traits may change as the mushrooms decay was not supported by our analyses. In the whole insect community, however, the percentage of variance explained by the environmental variable were rather small $(10-19 \%)$. Thus, although there is no clear evidence, it seems that differences in fungal genera do not greatly influence the composition of the whole insect community. Although they attack decaying mushrooms, members of the drosophilid community appear to be relatively sensitive to difference in the chemical traits of fungal genera, which has an effect on the species composition of the community.

In the drosophilid community, there was no overall effect of fungal genera, but some fungal genera significantly affected the species composition (Fig. 2). Drosophilid larvae feed on yeast or bacteria on substrates on which their parent lay eggs, and some drosophilids show a preference for specific yeasts or bacteria (Kearney \& Shorrocks, 1981; Oakeshott et al., 1989). The growth of some microbes is inhibited by sesquiterpenes produced by certain species of Agaricales (Lactarius vellereus: Sterner et al., 1985). Thus, it is likely that microbial floras differ among fungal genera, and drosophilid species may choose their hosts accordingly.

Bruns (1984) divided mycophagous insects into two groups: primary fungivores and secondary fungivores. Primary fungivores, such as Mycetophilidae and Phoridae, feed on fungal tissues and secondary fungivores, such as Drosophilidae and Psychodidae feed on the microbes living on mushrooms. In the partial CCA diagram, Mycetophilidae and Phoridae tended to be closely associated, as were the Drosophilidae and Psychodidae (Fig. 1). This suggests that there is some relationship between preference for particular developmental stages of fungi and that for particular fungal genera, although many insect families and drosophilid species in these plots occurs close to the origins, suggesting that they were likely to be polyphagous. Amanita mushrooms remain fresh for a shorter period than those of Lactarius (Yamashita \& Hijii, 2004), which suggests that Amanita mushrooms decay more quickly than those of Lactarius. Thus, differences in the perishability of mushrooms belonging to different fungal genera may affect the composition of the insect community exploiting mushrooms at a particular stage.

Mycophagous insects are adapted to the toxins present in fungal fruiting bodies (Hanski, 1989), at least those of their hosts. In the whole insect community, Nitidulidae, with only one species (Neopallodes inermis Reitter), occurs close to Collybia in the partial CCA ordination diagram (Fig. 1). Some species of Collybia produce cyanide, which is toxic to non-mycophagous insects, such as Drosophila melanogaster Meigen (Drosophilidae) and Spodoptera littoralis Boisduval (Noctuidae: Mier et al., 1996). Jaenike et al. (1983) tested the insecticidal properties of $\alpha$-amanitin and showed that it is not harmful to mycophagous drosophilids, but is a highly effective defense against non-mycophagous drosophilids.

The correspondence between the longevity of fungal hosts and the larval period of insects may also explain the pattern of host selection by mycophagous insects. Diptera have a short larval period and dominate in the short lived agaric fungi (Kimura, 1976; Hackman \& Meinander, 1979; Lacy, 1984; Yamashita \& Hijii, 2003), and Coleoptera a long larval period and dominate long lived polypores (Aphyllophorales; Pielou \& Verma, 1968; Hågvar, 1999, Jonsell et al., 2001). In mycophagous drosophilids, the longevity of their fungal host's fruiting body is similar to that of their larval period (Toda \& Kimura, 1997). In 
our previous study, we showed that nitidulid beetles, which have a long larval period, attack mushrooms of Collybia soon after they appeared (Yamashita \& Hijii, in press), when they may be toxic; thus, nitidulid beetles appear to select mushrooms that will last for a long time. These findings suggest that in mycophagous insects, selection pressure may be greater to use fruiting bodies with a suitable longevity rather than those that contain little or no defensive chemicals.

Our study showed that fungal genera, which may represent chemical compounds, only slightly affected the species composition of a mycophagous insect community, even during the early stages of development of the fungi. This finding suggests that for mycophagous insect communities, the chemical compounds produced by fungi are less likely to be important than other selection pressures. Thus, the quality hypothesis (Hanski, 1989) is the most likely explanation of the polyphagy in our system.

Our study did not evaluate the effect of low predictability of mushroom occurrence. Courtney et al. (1990) proposed that mushrooms produced by mycorrhizal fungi are more predictable resources for insects than those produced by saprophytic fungi, because mycorrhizal fungi have specific associations with particular tree species. In the study plots, however, the distribution of fruiting bodies of saprophytic fungi tended to be aggregated and changed very slowly (Yamashita \& Hijii, 2006). In addition, the insect communities did not show a clear association with either of these two fungal groups (Fig. 1). Thus, this study indicates that there is little difference in the predictability of the spatial distribution of mycorrhizal (Amanita, Cortinarius, Inocybe, Lactarius and Russula) and saprophytic fungi (Collybia, Marasmiellus, Marasmius, Mycena and Rhodophyllus). The low predictability of the occurrence of agaric mushrooms is likely to select for polyphagy in mycophagous insects, but its relative importance compared to other factors must be evaluated by further studies of the factors determining the structure of mycophagous insect communities on mushrooms.

ACKNOWLEDGEMENTS. We thank H. Yamada for identifying of the fruiting bodies. We are also grateful to M.J. Toda (Institute of Low Temperature Sciences, Hokkaido University) for identifying the drosophilid species and K. Yamazaki (Osaka City Institute of Public Health and Environmental Sciences) for identifying the nitidulid species. Thanks are also extended to N. Tuno (Institute of Tropical Medicine, Nagasaki University) for valuable suggestions. We also thank E. Shibata and $H$. Kajimura, Y. Imaizumi and N. Yamaguchi and the members of the Forest Protection Laboratory, Nagoya University, for valuable suggestions and helpful support. This study was partly supported by a Grant-in-Aid for JSPS Fellows (No. 15000810).

\section{REFERENCES}

AsHe J.S. 1984: Major features of the evolution of relationships between Gyrophaenine Staphylinid beetles (Coleoptera: Staphylinidae: Aleocharinae) and fresh mushrooms. In Wheeler Q. \& Blackwell M. (eds): Fungus-Insect Relationships, Perspectives in Ecology and Evolution. Columbia University Press, New York, pp. 227-255.

BRUNS T.D. 1984: Insect mycophagy in the Boletales: Fungivore diversity and the mushroom habitat. In Wheeler Q. \& Black- well M. (eds): Fungus-Insect Relationships, Perspectives in Ecology and Evolution. Columbia University Press, New York, pp. 91-129.

Courtney S.P., Kibota T.T. \& Singleton T.A. 1990: Ecology of mushroom-feeding Drosophilidae. Adv. Ecol. Res. 20: 225-274.

Daniewski W.M., Gumulka M., Ptaszynska K., Skibicki P., Bloszyk E., Drozdz B., Stromberg S., Norin T. \& Holub M. 1993: Antifeedant activity of some sesquiterpenoids of the genus Lactarius (Agaricales: Russulaceae). Eur. J. Entomol. 90: $65-70$.

Fäldt J., Jonsell M., Nordlander G. \& Borg-Karlson A. 1999: Volatiles of bracket fungi Fomitopsis pinicola and Fomes fomentarius and their functions as insect attractants. $J$. Chem. Ecol. 25: 567-590

Guevara R., Hutcheson K.A., Mee A.C., Rayner A.D.M. \& REYNOLDS S.E. 2000: Resource partitioning of the host fungus Coriolus versicolor by two ciid beetles: the role of odour compounds and host ageing. Oikos. 91: 184-194

Hackman W. \& Meinander M. 1979: Diptera feeding as larvae on macrofungi in Finland. Ann. Zool. Fenn. 16: 50-83.

HÅgVAR S. 1999: Saproxylic beetles visiting living sporocarps of Fomitopsis pinicola and Fomes fomentarius. Norw. J. Entomol. 46: 25-32

HANSKI I. 1989: Fungivory: fungi, insects and ecology. In Wilding N., Collins N.M., Hammond P.M. \& Webber J.F. (eds): Insect-Fungus Interactions. Academic Press, London, pp. $25-68$.

IMAZEKI R. \& Hongo T. 1987: Colored Illustrations of Mushrooms of Japan. Vol. I. Hoikusha, Osaka, 325 pp. [in Japanese].

IMAZEKI R. \& Hongo T. 1989: Colored Illustrations of Mushrooms of Japan. Vol. II. Hoikusha, Osaka, 315 pp. [in Japanese].

JAENIKE J. 1978: Resource apredictability and niche breadth in the Drosophila quinaria species group. Evolution 32: 676-678.

Jaenike J., Grimaldi D.A., Sluder A.E. \& Greenleaf A.L. 1983: $\alpha$-Amanitin tolerance in mycophagous Drosophila. Science 221: 165-167.

Jongman R.H.G., ter BraAK C.J.F. \& VAN TONGEREN O.F.R. 1995: Data Analysis in Community and Landscape Ecology. Cambridge University Press, Cambridge, 299 pp.

Jonsell M. \& Nordlander G. 2004: Host selection patterns in insects breeding in bracket fungi. Ecol. Entomol. 29: 697-705.

Jonsell M., Nordlander G. \& Ehnströn B. 2001: Substrate associations of insects breeding in fruiting bodies of wooddecaying fungi. Ecol. Bull. 49: 173-194.

KEARNEY J.N. \& Shorrocks B. 1981: The utilization of naturally occurring yeasts by Drosophila species, using chemically defined substrates. Biol. J. Linn. Soc. 15: 39-56.

KIMURA M.T. 1976: Drosophila survey of Hokkaido, XXXII. A field survey of fungus preferences of drosophilid flies in Sapporo. J. Fac. Sci., Hokkaido Univ. Ser. VI, Zool. 20: 288-298.

Komonen A. 2001: Structure of insect communities inhabiting old-growth forest specialist bracket fungi. Ecol. Entomol. 26: 63-75.

KUKOR J.J. \& MARTIN M.M. 1987: Nutritional ecology of fungus-feeding arthropods. In Slansky F.Jr. \& Rodriguez J.G. (eds): Nutritional Ecology of Insects, Mites, Spiders, and Related Invertebrates. John Wiley \& Sons, New York, pp. 791-814.

LACY R.C. 1984: Predictability, toxicity, and trophic niche breadth in fungus-feeding Drosophilidae (Diptera). Ecol. Entomol. 9: 43-54. 
LaWrence J.F. 1989: Mycophagy in the Coleoptera: Feeding strategies and morphological adaptations. In Wilding N., Collins N.M., Hammond P.M. \& Webber J.F. (eds): InsectFungus Interactions. Academic Press, London, pp. 1-23.

Mier N., Canete S., Klaebe A., Chavant L. \& Fournier D. 1996: Insecticidal properties of mushroom and toadstool carpophores. Phytochemistry 41: 1293-1299.

OAKeShOtT J.G., VACEK D.C. \& ANDERSON P.R. 1989: Effects of microbial floras on the distributions of five domestic Drosophila species across fruit resources. Oecologia 78: 533-541.

Pielou D.P. \& Verma A.N. 1968: The arthropod fauna associated with the birch bracket fungus, Polyporus betulinus, in eastern Canada. Can. Entomol. 100: 1179-1199.

Sterner O., Bergman R., Kinlberg J. \& Wickberg B. 1985: The sesquiterpenes of Lactarius vellereus and their role in a proposed chemical defense system. J. Nat. Prod. 48: 279-288.

TER BRAak C.J.F. \& Šmilauer P. 2002: CANOCO Reference Manual and CanoDraw for Windows User's Guide: Software for Canonical Community Ordination. version 4.5. Microcomputer Power, Ithaca, NY, 500 pp.

Toda M.J. \& Kimura M.T. 1997: Life-history traits related to host selection in mycophagous drosophilids. J. Anim. Ecol. 66: $154-166$.
Worthen W.B., Carswell M.L. \& Kelly K.A. 1996: Nested subset structure of larval mycophagous fly assemblages: nestedness in a non-island system. Oecologia 107: 257-264.

Worthen W.B., Jones M.T. \& Jetton R.M. 1998: Community structure and environmental stress: desiccation promotes nestedness in mycophagous fly communities. Oikos 81: 45-54.

Yamashita S. \& HiJII N. 2003: Effects of mushroom size on the structure of a mycophagous arthropod community: comparison between infracommunities with different types of resource utilization. Ecol. Res. 18: 131-143.

Yamashita S. \& HiJI N. 2004: Relationships between seasonal appearance and longevity of fruitbodies of Agaricales and meteorological factors in a Japanese red pine forest. J. For. Res. 9: 165-171.

Yamashita S. \& HiJII N. 2006: Spatial distribution of the fruiting bodies of Agaricales in a Japanese red pine (Pinus densiflora) forest. J. For. Res. 11: 181-189.

YAMASHita S. \& HiJi N. 2007: Resource use pattern of a mycophagous beetle, Neopallodes inermis (Coleoptera, Nitidulidae), on soft fungi, Collybia spp. (Agaricales). Ann. Entomol. Soc. Am. 100 (in press).

Received April 11,2006; revised and accepted December 4, 2006 